\title{
CONTRIBUIÇÃO DA REGIÃO CONTROLE DO MTDNA (D-LOOP) NO MONITORAMENTO GENÉTICO TEMPORAL DO CAMARÃO-ROSA FARFANTEPENAEUS PAULENSIS (PÉREZ-FARFANTE, 1967)
}

\author{
Teodoro, S.S.A. ${ }^{1,2,3, *}$; da Silva Cortinhas, M.C. ${ }^{2,3}$; Proietti, M.C. ${ }^{2}$; Costa, R.C. ${ }^{1}$ \& Dumont, L.F.C. ${ }^{3}$ \\ ${ }^{1}$ Universidade Estadual Paulista (UNESP), Campus Bauru, \\ Laboratório de Camarões Marinhos e de Água Doce (LABCAM). \\ ${ }^{2}$ Universidade Federal do Rio Grande (FURG), Campus Carreiros, \\ Laboratório de Ecologia Molecular Marinha (LEMM). \\ ${ }^{3}$ Universidade Federal do Rio Grande (FURG), Campus Carreiros, \\ Laboratório de Crustáceos Decápodes (LCD). \\ *Autor correspondente: sarahteodoro@gmail.com
}

O camarão rosa Farfantepenaeus paulensis representa um dos recursos pesqueiros mais explorados nas regiões sul e sudeste do Brasil. O crescimento irrestrito da frota industrial, juntamente com o aumento da pesca artesanal em áreas estuarinas e a baixa efetividade da legislação pesqueira, levaram ao colapso da pesca do camarão-rosa no final da década de 90. Uma das principais regiões de exploração do camarão rosa $F$. paulensis é o estuário da Lagoa dos Patos (costa sul do Brasil), cuja pesca artesanal é efetuada sobre o estrato juvenil do estoque e de forma muito intensa, muitas vezes dificultando a migração dos camarões para o oceano para completarem seu ciclo de vida. O gerenciamento de recursos naturais deve também considerar as respostas evolutivas à pesca, e o monitoramento genético é uma das maneiras mais eficientes para detectar mudanças genéticas causadas pela exploração. Nesse contexto, a diversidade genética e os padrões demográficos de F. paulensis foram comparados na costa sul do Brasil em dois períodos, antes (1990) e depois (2012) do colapso pesqueiro. Objetivou-se verificar se existe diferença genética entre as populações de F. paulensis antes e depois do colapso e investigar como o uso da região controle do mtDNA pode oferecer subsídios científicos em medidas de manejo de espécies exploradas. Os índices Fst e AMOVA revelaram diferenciação genética moderada $(0,11838)$ entre os dois períodos analisados. A diversidade haplotípica foi alta para os dois períodos, com uma diversidade nucleotídica ligeiramente maior em 2012. A análise de distribuição mismatch e os testes de neutralidade indicaram uma mudança no padrão de expansão populacional: em 1990 a população apresentava sinais de estabilidade, enquanto que em 2012 ela demonstrou sinais de expansão. Esse processo de aparente recuperação genética provavelmente foi possível devido a características intrínsecas de $F$. paulensis (como alta variabilidade no mtDNA, grande capacidade de recuperação populacional e alta dispersão larval), combinadas com a mudança na pescaria industrial de mono para multiespecífica, bem como alterações na política do defeso e aumento na fiscalização. Os resultados obtidos alertam para a importância do monitoramento contínuo da espécie, pois a recuperação de uma população que é constantemente explorada é um processo que pode envolver diversos parâmetros, taxas e níveis.

Palavras-chave: sobrepesca; diversidade genética; demografia populacional; monitoramento genético; manejo pesqueiro. 